\title{
O atletismo nos cursos de graduação em Educação Física
}

\author{
Eduardo Vinícius Mota e Silva ${ }^{1}$ \\ Suraya Cristina Darido ${ }^{2}$ \\ ${ }^{1}$ CCBS - Universidade Presbiteriana Mackenzie, Barueri, SP, Brasil. \\ ${ }^{2}$ Instituto de Biociências. UNESP - Univ Estadual Paulista, Campus de Rio Claro, \\ Departamento de Educação Física, Laboratório de Estudos e Trabalhos Pedagógicos em \\ Educação Física Escolar (LETPEF), Rio Claro, SP, Brasil
}

Resumo: Este estudo propõe-se a investigar o papel e as características do ensino das disciplinas relacionadas à modalidade esportiva Atletismo em quatro cursos de graduação em Educação Física do estado de São Paulo. Para isto, utilizou-se de uma pesquisa do tipo qualitativa. Os dados foram coletados por meio de análise documental das ementas e programas; da observação de aulas e de entrevistas realizadas com professores e alunos das instituições (duas públicas e duas privadas) responsáveis por estes cursos. Por meio destas análises verificou-se que estas disciplinas têm superado algumas características relativas ao modelo curricular tradicional - esportivo. Quanto ao papel destas disciplinas, notou-se que os docentes a consideram como as responsáveis por dar condições básicas aos alunos, para que possam usufruir a modalidade esportiva como instrumental para as intervenções no mercado de trabalho.

Palavras-chave: Atletismo. Formação Profissional. Currículo.

\section{The athletics in physical education undergraduate courses}

Abstract: This study has the purpose to investigate the characteristics and the role of the athletics-related sports disciplines in four Physical Education undergraduate courses. In order to reach the goal, it was conducted as a qualitative-type research. Data was collected through documental analysis on disciplines briefings and programs, and also from classes observations and interviews with professors and students from the institutions (two State-boarded and two private) responsible for the courses. Through these analyses it was perceived that those disciplines have surpassed some characteristics of the traditional undergraduate program, which is based on sports. Regarding the role of the disciplines, it was noted that professors consider them as responsible for providing students with basic conditions, so they could benefit from sports as instrumental subjects for their professional intervention.

Key Words: Athletics. Professional Education. Undergraduate Program.

\section{Introdução}

As disciplinas esportivas, tradicionalmente, ocupam grande espaço nos currículos dos cursos de graduação em Educação Física e têm colecionado, durante este período, uma série de críticas ao seu desenvolvimento (DARIDO; SILVA, 2002). Estas críticas, de forma geral, prendem-se ao fato de que são ministradas priorizando a vivência de habilidades motoras por meio de seqüências executadas pelos próprios alunos, limitando seus conteúdos teóricos ao ensino de regras e estratégias esportivas, além de manterem-se isoladas das demais disciplinas e dos objetivos gerais dos cursos de graduação (PIROLO, 1997; TANI, 1996; TERRA, 1997), características, estas, de um modelo curricular classificado como tradicional esportivo por Rangel-Betti e Betti (1996).
Destas críticas, talvez a mais discutida seja a da pertinência e utilidade de os acadêmicos vivenciarem as habilidades motoras específicas das modalidades esportivas. Alguns autores afirmam que esta vivência é bastante válida desde que seja um momento de experimentação (mas não o único) e esteja relacionada à aquisição de conhecimentos mais amplos, necessários à sua futura intervenção profissional (DE SANTO, 1997; NASCIMENTO et al., 2009; TANI, 1996). É ponto pacífico, também, que a vivência destas habilidades durante o curso de graduação não garante sua execução com grande qualidade e que, desta forma, não se deve acreditar que o ensino destas dependa, exclusivamente, da capacidade de demonstrá-las (TANI, 1996); muito embora, conforme Figueiredo (2004), um grande número de alunos ainda 
associe o saber executar ao pleno domínio dos conhecimentos da modalidade esportiva.

O corpo docente responsável pelo ensino destas disciplinas, tradicionalmente, apresenta como característica a experiência como atleta e/ou técnico de suas respectivas modalidades e, muitas vezes, acredita que esta experiência é mais importante do que o seu conhecimento teórico, assim como crê que a prática seja fundamental para a futura atuação do professor (PIROLO, 1997).

Dentre este conjunto de disciplinas, o Atletismo quase sempre está presente no currículo dos cursos de formação da área. Esta presença se deve, muitas vezes, à sua tradição e importância histórica e, também, à crença generalizada de que a mesma seja básica (esporte-base) para a aprendizagem de outras modalidades esportivas. Acredita-se que os problemas que aparecem nas demais disciplinas esportivas também estejam presentes aqui, e que, por suas peculiaridades alguns deles sejam potencializados pelo fato de o Atletismo não constituir uma das modalidades mais difundidas e vivenciadas no Brasil, ao menos no ambiente escolar, e que este se baseie, tradicionalmente, em resultados absolutos, fazendo com que se acredite que só possa ser realizado em condições próximas do esporte institucionalizado ( $\underline{\mathrm{ORO}}$, 1983; FREITAS JÚNIOR, 1994; LENCINA; ROCHA JÚNIOR, 2001; MATTHIESEN, 2005; MATTHIESEN, 2007; MARQUES; IORA, 2009).

Ao se considerar estas características e o fato de 0 pesquisador ser docente da referida disciplina, fez-se a opção, neste trabalho, por discutir-se a problemática das disciplinas esportivas nos cursos de graduação em Educação Física, tendo-se em vista a verificação do papel e das características atuais do ensino das disciplinas relacionadas à modalidade esportiva Atletismo em 4 (quatro) cursos de formação em Educação Física. Esta preocupação torna-se ainda mais relevante quando se sabe que muito pouco se tem discutido sobre o processo de ensino-aprendizagem das modalidades esportivas, especificamente, no âmbito do ensino superior (REZER, 2010) e que esta é uma discussão fundamental neste momento da formação inicial na área, após a implementação de novas diretrizes curriculares (DARIDO; SILVA, 2002).

\section{Método}

Optou-se, para o desenvolvimento deste trabalho, pela realização de uma pesquisa do tipo qualitativa. A amostragem foi intencional e composta por quatro instituições de ensino superior do Estado de São Paulo, sendo duas públicas (IPU 1 e IPU 2), que ofereciam tanto o bacharelado quanto a licenciatura e duas privadas (IPA 1 e IPA 2), que ofereciam exclusivamente a licenciatura. A escolha destes dois tipos de instituições se deu para que se garantisse uma visão mais ampla da questão investigada.

A coleta de dados foi composta por três instrumentos: a análise documental, a observação de aulas e a entrevista, com a intenção de se investigar o problema de forma bastante ampla e garantir a credibilidade do estudo, por meio da triangulação de três diferentes fontes de pesquisa, pois conforme Patton (2002), nenhum método sozinho é capaz de apresentar de forma adequada à realidade.

$\mathrm{Na}$ análise documental foram estudadas as grades curriculares dos cursos de graduação em Educação Física, além de programas, ementas, competências finais e carga horária das disciplinas relacionadas às modalidades esportivas com ênfase no Atletismo.

Por meio de entrevistas semi-estruturadas, realizadas com os docentes responsáveis pela referida disciplina e seus alunos, buscaram-se informações que auxiliassem na identificação da ligação entre o discurso docente e os objetivos dos respectivos cursos, o programa de suas disciplinas e os objetivos que vislumbrariam para as mesmas. Foram entrevistados, ainda, três alunos participantes da referida disciplina em cada uma das instituições, com o objetivo de se verificar a expectativa e o entendimento da disciplina por parte do corpo discente.

Na observação de aulas buscou-se enfatizar a análise de sua globalidade. Para tal, foram observadas quatro aulas de cada instituição. Esta análise teve por objetivo checar e complementar as informações obtidas pelas entrevistas. A observação ocorreu de forma não participante, por meio de descrição e anotação dos principais eventos das mesmas. Para o registro destas observações, utilizou-se de anotações de campo de natureza descritiva, com ênfase nos seguintes aspectos: comportamentos dos sujeitos, descrição do meio, das atividades e dos diálogos (TRIVIÑOS, 1987). Todas as etapas desta 
pesquisa contaram com a autorização dos responsáveis pelas instituições, dos professores e dos alunos envolvidos.

A partir dos resultados obtidos com estes três instrumentos de análise, procurou-se selecionar e dividir os dados em categorias que viessem a apresentar o papel destas disciplinas, bem como suas características. Entende-se aqui como papel a função desempenhada por estas nos cursos de graduação em Educação Física e, por conseguinte, na formação do aluno. Para a verificação das características principais das disciplinas relacionadas ao Atletismo, buscou-se organizar os dados nos seguintes aspectos: ambiente e materiais utilizados na realização das aulas; os conteúdos desenvolvidos e sua classificação; os modelos de aula desenvolvidos, com ênfase nas atividades dos docentes e discentes; e a questão da vivência de habilidades motoras.

\section{Resultados}

Apresenta-se no quadro abaixo uma síntese das principais percepções referentes às características de ensino das disciplinas relacionadas ao Atletismo, nas diferentes instituições.

Quadro 1 - Papel e características das disciplinas esportivas relacionadas ao Atletismo.

\begin{tabular}{|c|c|c|c|c|}
\hline INSTITUIÇÃO & IPA 1 & IPA 2 & IPU 1 & IPU 2 \\
\hline Papel & $\begin{array}{l}\text { Base para a } \\
\text { compreensão da } \\
\text { Educação Física. }\end{array}$ & $\begin{array}{l}\text { Aplicação e } \\
\text { desenvolvimento de } \\
\text { competências gerais. }\end{array}$ & $\begin{array}{l}\text { Compreensão da } \\
\text { modalidade e suas } \\
\text { possibilidades de } \\
\text { trabalho. }\end{array}$ & $\begin{array}{l}\text { Compreensão da } \\
\text { modalidade enquanto } \\
\text { desporto e atividade } \\
\text { motora. }\end{array}$ \\
\hline Local & $\begin{array}{l}\text { - Pista de Atletismo } \\
(75 \%) \\
\text { - Sala de aula }(25 \%) \text {. }\end{array}$ & $\begin{array}{l}\text { - Não específicos } \\
\text { (quadra e sala de } \\
\text { ginástica) } \\
\text { - Específico adaptado. }\end{array}$ & $\begin{array}{l}\text { - Pista de Atletismo } \\
\text { (100\%) com utilização de } \\
\text { espaços específicos e } \\
\text { não específicos às provas } \\
\text { ensinadas. }\end{array}$ & $\begin{array}{l}\text { - Sala de aula (75\%) } \\
\text { - Pista de Atletismo } \\
\text { (25\%) (espaços } \\
\text { específicos e não } \\
\text { específicos às provas } \\
\text { ensinadas) }\end{array}$ \\
\hline Materiais & $\begin{array}{l}\text { - Específicos } \\
\text { - Oficiais }\end{array}$ & $\begin{array}{l}\text { - Específicos } \\
\text { - Oficiais } \\
\text { - Auxiliares }\end{array}$ & $\begin{array}{l}\text {-Específicos } \\
\text { - Oficiais } \\
\text { - Adaptados }\end{array}$ & $\begin{array}{l}\text { - Específicos } \\
\text { - Oficiais } \\
\text { - Pedagógicos }\end{array}$ \\
\hline Conteúdos & $\begin{array}{l}\text { - Critérios de } \\
\text { avaliação. } \\
\text { - Treinamento prático. } \\
\text { - Organização de } \\
\text { evento. }\end{array}$ & $\begin{array}{l}\text { - Provas (seqüências de } \\
\text { ensino, técnicas, } \\
\text { avaliação prática). }\end{array}$ & $\begin{array}{l}\text { - Provas (regras, ensino, } \\
\text { segurança, técnicas, } \\
\text { jogos) } \\
\text { - Atualidades sobre a } \\
\text { modalidade. }\end{array}$ & $\begin{array}{l}\text { - Provas (técnica, } \\
\text { exercícios, regras e } \\
\text { seqüências de ensino). }\end{array}$ \\
\hline $\begin{array}{c}\text { Ação } \\
\text { docente }\end{array}$ & $\begin{array}{l}\text { - Controle da } \\
\text { freqüência } \\
\text { - Preparação dos } \\
\text { materiais } \\
\text { - Controle do período } \\
\text { de aquecimento } \\
\text { - Observação e } \\
\text { correção da execução } \\
\text { dos alunos } \\
\text { - Esclarecimento de } \\
\text { dúvidas } \\
\text { - Mediação de } \\
\text { conflitos. }\end{array}$ & $\begin{array}{l}\text { - Preparação e } \\
\text { organização do } \\
\text { ambiente. } \\
\text { - Demonstração oral e } \\
\text { corporal. } \\
\text { - Controle da } \\
\text { intensidade da atividade. } \\
\text { - Observação e correção } \\
\text { da execução dos alunos. }\end{array}$ & $\begin{array}{l}\text { - Ensino do conteúdo. } \\
\text { - Motivação dos alunos. } \\
\text { - Auxílio à organização } \\
\text { dos alunos para a } \\
\text { atividade. } \\
\text { - Observação e correção } \\
\text { da execução. } \\
\text { - Demonstração oral e } \\
\text { corporal. } \\
\text { - Esclarecimento de } \\
\text { dúvidas. }\end{array}$ & $\begin{array}{l}\text { - Ensino do conteúdo. } \\
\text { - Observação e correção } \\
\text { da execução. } \\
\text { - Demonstração oral e } \\
\text { corporal. } \\
\text { - Esclarecimento de } \\
\text { dúvidas. }\end{array}$ \\
\hline $\begin{array}{l}\text { Atividades } \\
\text { dos alunos }\end{array}$ & $\begin{array}{l}\text { - Execução das } \\
\text { atividades. } \\
\text { - Auxílio e correção } \\
\text { da execução dos } \\
\text { colegas. } \\
\text { - Organização de } \\
\text { evento. }\end{array}$ & $\begin{array}{l}\text { - Execução das } \\
\text { atividades. } \\
\text { - Elaboração de } \\
\text { questionamentos. }\end{array}$ & $\begin{array}{l}\text { - Execução das atividades } \\
\text { - Realização de } \\
\text { seminários. } \\
\text { - Observação e correção } \\
\text { da execução dos colegas. } \\
\text { - elaboração e resposta } \\
\text { de questionamentos. }\end{array}$ & $\begin{array}{l}\text { - Acompanhamento de } \\
\text { aula teórica. } \\
\text { - Elaboração e resposta } \\
\text { de questionamentos. }\end{array}$ \\
\hline
\end{tabular}

\section{Análise e Discussão dos Resultados}

\section{O papel das disciplinas relacionadas ao atletismo}

Para a verificação do papel desempenhado pelas disciplinas relacionadas ao Atletismo nos cursos observados, buscou-se verificar, inicialmente, as ementas e os programas das quatro instituições analisadas.
A partir desta análise notou-se que a maior parte das instituições procura apresentar as referidas disciplinas em dois momentos: um dedicado aos conhecimentos básicos da modalidade e outro ao seu aprofundamento, como é o caso das IPU1, IPU2 e IPA2. Esta característica representa uma inovação, pois, tradicionalmente, tais disciplinas eram divididas 
levando-se em consideração apenas suas provas e não a necessidade de aprofundamento entre as etapas.

Com relação aos programas destas disciplinas, verificou-se que, com exceção da IPA 1 , todos eles refletem uma preocupação em se trabalhar com os aspectos pedagógicos. Esta intenção manifestada parece representar uma resposta às críticas, já citadas, ao modelo de ensino tradicional vivenciado pelas disciplinas em questão e, talvez, a uma percepção de que também é função das mesmas ajudar o aluno a aprender a ensinar.

$\mathrm{Na}$ IPA 1, porém, conforme citado, o entendimento desta questão é bastante diferenciado, pois o docente desta instituição possui o seguinte ponto de vista:

o objetivo da matéria Atletismo não é ensinar a ensinar (...) têm duas ou três matérias na faculdade que ensinam a ensinar. Eu dou os conhecimentos básicos de Atletismo (...) eu poderia até dar mas não tem tempo hábil, certo, então (...) passo a matéria e ele tem que correlacionar com as outras disciplinas para chegar no conhecimento necessário para aplicar.

Entendimento este, que apesar de apresentar certa coerência, mostra uma visão em que se coloca toda a responsabilidade em integrar os conhecimentos, dados no curso, apenas aos alunos, o que de certa forma contraria uma vertente mais atual dos modelos de formação profissional, a perspectiva reflexiva, na qual se entende que todas as disciplinas devem buscar uma integração maior, com o intuito de potencializar 0 processo de preparação do profissional do aluno, que irá atuar em um ambiente complexo, no qual terá que utilizar estes conhecimento de forma integrada (DARIDO; SILVA, 2002). Reforçando este entendimento, Rezer (2010) afirma que é necessário que o docente universitário entenda que enfatizar 0 simples domínio dos conteúdos específicos da modalidade não é suficiente, pois ele não pode se esquecer que participa

de um processo de construção do conhecimento necessário para que a futura intervenção pedagógica não se reduza à simples reprodução, desenvolvendo as competências necessárias para que tenham possibilidades de oportunizar aos seus alunos a reconstrução inteligente, competente e contextualizada (se possível, prazerosa,) em aulas críticas, de conteúdos pertinentes à cultura corporal de movimento (REZER, 2010, p. 275).
Ao se analisar o discurso dos docentes, em geral, percebeu-se que quando perguntados, diretamente, sobre a função desempenhada por suas disciplinas, ficam nítidos dois entendimentos: 0 primeiro que vê nestas disciplinas um fim em si, ou seja, que a função dela é instrumentalizar 0 aluno com um conhecimento amplo da modalidade, porém, capacitando-o tão somente para a atuação com o Atletismo. E o outro que a vê como um conhecimento básico para a área de Educação Física, como um todo, por ser uma modalidade que trabalha com os movimentos básicos do ser humano.

O mesmo acontece ao se analisar o discurso dos alunos, pois para eles, também, as contribuições das disciplinas relacionadas ao Atletismo para a sua formação ou são específicas, ou seja, têm como função preparálos para trabalhar tão somente com a modalidade, seja em ambiente escolar ou não, ou que a aprendizagem obtida nesta disciplina é fundamental, por ser base para todas as outras modalidades, pelo fato de trabalhar com os principais movimentos básicos do ser humano.

\section{O ambiente das aulas}

O local mais utilizado para a realização das aulas analisadas foi a pista de Atletismo. Porém, nem sempre se utilizou o local específico da prova em questão, ou seja, nem sempre se ensinava o arremesso de peso, por exemplo, no círculo de arremessos, mas sim em outros locais como o gramado existente no centro das pistas. Este fator demonstra a preocupação de alguns docentes, dentre os quais se destaca o da IPU 1 , em se trabalhar com o Atletismo em um ambiente diferenciado, para demonstrar aos alunos que esta modalidade pode ser ensinada em uma diversidade de ambientes. A única instituição que não se utilizou deste local foi a IPA 2, em virtude de a mesma não contar com uma pista, mas apenas um espaço adaptado.

Esta preocupação demonstrada pelos docentes, de aproximar o ensino do Atletismo da realidade encontrada em clubes e escolas, representa um grande avanço que pode significar a modificação daquela característica percebida por Freitas Júnior (1994): de que os cursos transmitem a idéia de que só é possível ensinar Atletismo caso haja uma pista e materiais específicos para tal; muito embora, ainda hoje, alguns estudos demonstrem que 0 maior 
empecilho para se trabalhar com o Atletismo na escola, na visão dos professores, seja a ausência de infra- estrutura (LENCINA; ROCHA, 2001; MARQUES; IORA, 2009).

Poucas aulas observadas foram realizadas em sala de aula. Na IPA 1 a sala de aula foi utilizada, de certa forma, como punição ao grupo de alunos que reclamou dos critérios de avaliação do professor, pois, conforme afirmado por ele, não haveria mais aulas práticas até que a situação do protesto fosse resolvida. Na IPU 2, a sala de aula foi utilizada na maior parte das aulas observadas, o que pode se justificar pelas características desta disciplina, que era de aprofundamento para o curso de bacharelado e exigia uma grande carga conceitual, a prática era utilizada apenas como um espaço para experimentação / comprovação da teoria, conforme enfatizado pelo docente em diversas aulas.

De forma geral, ficou caracterizada na maioria dos momentos aquela divisão existente nas disciplinas esportivas, em que as aulas teóricas ocorrem em sala de aula e as práticas nos campos, pistas, quadras e piscinas, conforme já verificado em estudos de Rangel-Betti e Betti (1996) e Terra (1997).

A maior parte dos professores, no entanto, procurava, durante as aulas observadas, tratar de conteúdos trabalhados em sala de aula durante a realização de atividades por parte dos alunos, ou seja, procuravam mantê-los informados a respeito das finalidades das atividades que estavam sendo realizadas. Esta preocupação é importante, principalmente, por vir de encontro ao que foi notado por De Santo (1997), em estudo realizado por ele com alunos do último ano da primeira turma de bacharelado da USP, em que verifica que os alunos não querem mais um modelo de aula em que tenham que treinar ou jogar, como se fossem estas atividades um fim em si próprias, mas, sim, uma aula em que a atividade fosse desenvolvida de forma integrada aos conhecimentos fundamentais vistos em sala de aula.

\section{Os materiais utilizados nas aulas}

Com relação aos materiais utilizados nas aulas, houve uma grande diversidade, os quais podem ser classificados em três tipos: específicos à modalidade, implementos oficiais e auxiliares à aprendizagem da modalidade; adaptados, materiais de fácil aquisição e não específicos à modalidade, adaptados para tal; e, recursos tecnológicos.

Notou-se uma relativa preocupação por parte de alguns docentes, principalmente o da IPU 1, em se utilizar de materiais simples, como jornal, cordas, bolas para as suas aulas. Esta preocupação demonstra, mais uma vez, o interesse do docente em apresentar o Atletismo como uma modalidade possível de ser ensinada, mesmo sem contar com os equipamentos oficiais da mesma, o que vem de encontro à expectativa de se tornar o ensino do Atletismo algo mais próximo e real para $O$ aluno de graduação (FREITAS JÚNIOR, 1994; LENCINA e ROCHA JÚNIOR, 2001; MATTHIESEN, 2005; MATTHIESEN, 2007; ORO, 1983).

\section{Conteúdos desenvolvidos}

Os conteúdos trabalhados foram, basicamente, os blocos de provas da modalidade Atletismo. Em uma instituição (IPU 1), entretanto, o docente afirmou buscar incluir questões sóciohistóricas e educacionais aos conteúdos. Esta preocupação, bastante legítima, é fundamental para que os alunos percebam que 0 conhecimento a ser aprendido "não se resume á 'experiência-em-si', pois o acadêmico precisa dominar mais elementos que aqueles necessários à simples prática do esporte em questão" (REZER, 2010, p. 279).

Para desenvolverem estes conteúdos os docentes contam com uma carga horária bem menor do que a existente anteriormente e todos eles a consideram pequena em relação ao grande número de provas existentes no Atletismo. Porém, a maior parte deles procura adaptar-se à carga horária disponível, sem diminuir os conteúdos a serem tratados. Faz-se importante ressaltar, no entanto, que esta diminuição, muitas vezes, deveu-se mais a uma simples readequação (diminuição) do espaço dedicado às disciplinas esportivas "que por uma transformação qualitativa no entendimento do fenômeno esportivo no campo do ensino superior em EF". (REZER, 2010, p. 275). Inclusive, neste caso, pode-se questionar esta diminuição drástica no caso do Atletismo ou, até mesmo, o seu oferecimento, conjuntamente, com outras modalidades esportivas individuais quando se sabe da diversidade de provas abarcadas pela modalidade. 
É importante notar a preocupação, por parte dos docentes, de ensinar aos alunos todas as provas do Atletismo, mesmo sem contar com um grande tempo disponível para isso. Apenas o docente da IPA 1 optou por trabalhar com apenas algumas destas provas. Crê-se que esta seja uma preocupação a ser repensada, pois como se trata de um curso de formação inicial, não se sabe até que ponto seria importante tratar de todas as provas da modalidade, principalmente se observadas somente em seus aspectos técnicos. Concorda-se, neste ponto, com o entendimento expresso por Oro (1983) de que, para se tornar o conteúdo do Atletismo mais agradável, seria necessário escolher as provas com mais condições de serem praticadas e não aquelas que fazem parte do regulamento internacional da modalidade. Outra solução possível seria ensinar as diferentes provas do Atletismo, dentro de seus grupos, de forma integrada, com ênfase em seus aspectos comuns (invariantes), a exemplo do proposto por Daólio (2002) para os esportes coletivos.

\section{Dimensões dos conteúdos trabalhados}

Para caracterizar melhor o conteúdo desenvolvido pelos professores utilizou-se a classificação proposta por Coll (2000), na intenção de se verificar a ênfase dada pelos docentes a cada uma de suas dimensões: as conceituais, que envolvem fatos e conceitos; as procedimentais, que envolvem os procedimentos; $\mathrm{e}$, as atitudinais, que trabalham as atitudes, normas e valores.

Desta forma, notou-se, nas aulas observadas, que apesar de os cursos, ainda hoje, enfatizarem os conteúdos procedimentais, os mesmos passaram a incluir uma boa carga dedicada aos conteúdos conceituais em suas disciplinas, o que pode representar, mais uma vez, uma resposta às críticas estabelecidas ao modelo curricular esportivo e uma conseqüente aproximação ao modelo curricular científico, que valoriza este último tipo de conteúdos (DARIDO; SILVA, 2002).

Ainda com relação aos conteúdos procedimentais, é importante salientar que durante as aulas observadas eles foram de dois tipos: um, em que os alunos atuavam apenas executando os movimentos solicitados pelos professores, e outro no qual os mesmos atuavam como docentes. Este quadro demonstra que tais disciplinas estão passando por um momento de transição, no qual os alunos atuam cada vez menos como executantes e mais como docentes, chegando cada vez mais a aproximar-se do preconizado pelo modelo reflexivo, no qual os alunos devem ter o contato com a docência em todos os momentos do curso (DARIDO; SILVA, 2002).

Em algumas das instituições observadas foram tratados também conteúdos atitudinais, pois constantemente os professores cobravam de seus alunos posturas necessárias a um bom professor e respeito a algumas regras para o bom desenvolvimento das aulas. Entretanto, este tratamento se limitava, na maior parte das vezes, a uma correção de comportamento durante as aulas. Em poucos momentos percebeu-se a preocupação de se desenvolver em aula o ensino específico ou mesmo, como defendem os Parâmetros Curriculares Nacionais, a autonomia na construção de valores (BRASIL, 1998).

\section{Metodologia de ensino}

As atividades desenvolvidas pelos professores nas aulas observadas levaram a perceber que os mesmos quase sempre as centralizavam, ou seja, decidiam as atividades a serem executadas pelos alunos. Em alguns momentos, comunicados anteriormente ou não, algumas destas atividades eram delegadas aos alunos. A rotina de trabalho dos docentes consistia em: explicar e demonstrar oral ou corporalmente as atividades a serem executadas e após este momento acompanhar, explicar e corrigir as execuções dos alunos, além de incentivá-los a participarem das aulas.

De forma geral percebeu-se que comparativamente às características apresentadas anteriormente por estas disciplinas, vistas por meio da revisão bibliográfica, os alunos passam cada vez mais a ter contato com a docência no decorrer da disciplina, pois os professores parecem ter percebido que esta é a função primordial de um curso de formação profissional em Educação Física. Apesar desta evolução, acredita-se que o momento dedicado a estas experiências é ainda muito pequeno e seria importante que os docentes percebessem que, como afirmam Abreu e Masetto (1990), o seu papel, dentre outras coisas, não é somente “... ensinar, mas ajudar o aluno a aprender; não é transmitir informações, mas criar condições para que o aluno adquira informações..." (ABREU; MASETTO, 1990, p. 11). 


\section{$A$ vivência de habilidades motoras}

Com relação à vivência de habilidades motoras da modalidade, durante as aulas, todos os alunos a consideraram muito importantes. Apenas suas justificativas foram diferenciadas. Um grupo afirma que elas são uma forma de compreender como o executante se sente durante o movimento. Outro crê que elas são fundamentais para que se possa demonstrar aos alunos o como fazer, a fim de ensiná-los. Um número menor de alunos acha que facilita a aprendizagem do movimento.

Com relação a estes resultados é importante destacar que uma boa parte dos alunos vê esta oportunidade de vivenciar as habilidades motoras específicas do desporto como uma possibilidade de se conhecer o movimento, para que tenham condições de compreender como ocorre a aprendizagem de seus alunos. Esta compreensão é interessante, pois os alunos passam a ver as vivências motoras como um espaço para terem contato com um movimento, que muitas vezes desconhecem, e não como um momento para demonstrarem suas performances. Entretanto, parece ser um tanto ingênuo querer perceber, por meio da própria execução, como se dá a aprendizagem em outros, principalmente quando se sabe que na maioria das vezes os alunos atuarão com pessoas de diferentes faixas etárias. O ideal seria que entendessem estas práticas como fundamentais para a compreensão de sua futura atuação docente (NASCIMENTO et al., 2009) ou mesmo para a compreensão da atividade (FIGUEIREDO, 2004).

Fica perceptível, também, que os docentes têm procurado desatrelar a questão das vivências práticas da performance. Em diversos momentos eles afirmam não cobrar de seus alunos a performance, no entanto, alguns deles recorrem a provas de demonstração do gesto, chamadas por eles de práticas. Estas provas, porém, segundo os docentes, servem para verificar se os alunos aprenderam o movimento e não o seu nível de execução. Este resultado é reproduzido por alguns dos alunos, os quais afirmam que os docentes não cobram performance. Tal fato não foi encontrado nos alunos da IPA 1, para os quais, apesar de o professor tentar explicar o contrário, um desempenho mínimo é cobrado.

\section{Considerações Finais}

Pela análise conjunta dos três instrumentos utilizados (análise documental, entrevistas e observação de aulas) percebeu-se, neste estudo, que as disciplinas relacionadas à modalidade esportiva Atletismo, de forma geral, nas instituições analisadas têm passado por um processo de modificação de suas características, pois vão deixando de se pautar em algumas características típicas do modelo de formação tradicional - esportivo, e vão incluindo, cada vez mais, aspectos que podem ser atribuídos a um modelo de formação mais técnico - científico, por meio da valorização de questões teóricas. Não obstante, notou-se, em alguns momentos, a presença de aspectos que podem ter sido influenciados pelo modelo de formação do profissional reflexivo. Em relação à modalidade esportiva Atletismo, especificamente, notou-se que a maior parte dos docentes responsáveis pelo seu desenvolvimento tem procurado desenvolvê-la de forma mais próxima á realidade das condições de ensino no Brasil, na tentativa de modificarem aquela visão tradicional de que para se ensinar o Atletismo é necessário ter uma pista e materiais específicos.

\section{Referências}

ABREU, M. C.; MASETTO, M. T. O professor universitário em aula: prática e princípios teóricos. São Paulo: Associados, 1990.

BRASIL. Ministério da Educação e do Desporto. Secretaria de Educação Fundamental.

Parâmetros Curriculares Nacionais: Educação

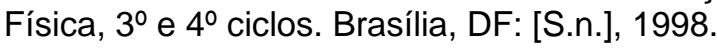

COLL, C. Introdução. In: COLL C. et al. Os conteúdos na reforma: ensino e aprendizagem de conceitos, procedimentos e atitudes. Porto Alegre: Artes Médicas, 2000. p. 9-16.

DAÓLIO, J. Jogos esportivos coletivos: dos princípios operacionais aos gestos técnicos modelo pendular a partir das idéias de Claude Bayer. Revista Brasileira Ciência e Movimento, Brasília, v. 10, n. 4, p. 99-104, out. 2002.

DARIDO, S. C.; SILVA, E. V. M. e. O papel das disciplinas esportivas na formação profissional em Educação Física. In: MOREIRA, W. W.; SIMÕES, R. (Org.). Esporte como fator de qualidade de vida. Piracicaba: UNIMEP, 2002. p. 151-162.

DE SANTO, D. L. Pontos a considerar sobre a avaliação do curso de bacharelado em educação física: turma 1995. Caderno Documento, São Paulo, v. 3, p. 73-91, 1997.

FIGUEIREDO, Z. C. C. Formação docente em educação física: experiências sociais e relação 
com o saber. Movimento, Porto Alegre, v. 10, n. 1, p. 89-111, jan./abr. 2004. Disponível em: <http://seer.ufrgs.br/Movimento/article/view/2827/ 1441>. Acesso em: 23 abr. 2011.

FREITAS JÚNIOR, M. A. A educação motora através do atletismo na escola. In: ENCONTRO NACIONAL DE HISTÓRIA DO ESPORTE, LAZER E EDUCAÇÃO FÍSICA, 2., 1994, Ponta Grossa. Coletânea... Ponta Grossa: Universidade Estadual de Ponta Grossa, 1994, p. 161-174.

LENCINA, L. A.; ROCHA JÚNIOR, I. C. Diagnóstico do atletismo escolar em Santa Maria. Kinesis, Santa Maria, n. 25, p. 71-89, 2001.

MARQUES, C. L. S.; IORA, J. A. Atletismo escolar: possibilidades e estratégias de objetivo, conteúdo e método em aulas de educação física. Movimento, Porto Alegre, v. 15, n. 2, p. 103-118, abr./jun. 2009. Disponível em:

$<$ http://seer.ufrgs.br/Movimento/article/download/3 078/5137>. Acesso em: 11 jun. 2010.

\section{MATTHIESEN, S. Q. (Org.). Atletismo se} aprende na escola. Jundiaí, SP: Fontoura, 2005.

MATTHIESEN, S. Q. Atletismo: teoria e prática. Rio de Janeiro: Guanabara Koogan, 2007.

NASCIMENTO, J. V. et al. Formação acadêmica e intervenção pedagógica nos esportes. Motriz, Rio Claro, v. 15, n. 2, p. 358-366, 2009. Disponível em:<http://www.periodicos.rc.biblioteca.unesp.br/i ndex.php/motriz/article/view/2251/2378 >. Acesso em: 11 jun. 2010

ORO, U. Iniciação ao atletismo no Brasil: problemas e possibilidades didáticas. In: $\mathrm{KIRSCH}$, A.; $\mathrm{KOCH}, \mathrm{K}$; $\mathrm{ORO}, \mathrm{U}$. Antologia do atletismo: metodologia para iniciação em escolas e clubes. Rio de Janeiro: Ao Livro Técnico, 1983.

\section{PATTON, M. Q. Qualitative research and} evaluation methods. Thousand Oaks: Sege Publications, 2002.

PIROLO, A. L. A disciplina voleibol nos cursos de licenciatura em educação física do Paraná: processo de conhecimento crítico reflexivo? In: COSTA, V. L. M. (Org.). Formação profissional universitária em educação física. Rio de Janeiro: Uiversidade Gama Filho, 1997. p. 161200.

RANGEL-BETTI, I. C.; BETTI, M. Novas perspectivas na formação profissional em educação física. Motriz, Rio Claro, v. 2, n. 1, p. 10-15, 1996. Disponível em: $<$ http://www.rc.unesp.br/ib/efisica/motriz/02n1/V2n 1 ART02.pdf>. Acesso em: 13 abr. 2009.
REZER, R. Reflexões didático-pedagógicas acerca do ensino do esporte no processo de formação de professores de Educação Física. Movimento, Porto Alegre, v. 16, n. 1, p. 271-292, jan./mar. 2010. Disponível em:

$<$ http://seer.ufrgs.br/Movimento/article/download/5 719/7528 >. Acesso em: 11 jun. 2010.

TANI, G. Cinesiologia, Educação Física e esporte: ordem emergente do caos na estrutura acadêmica. Motus Corporis, Rio de Janeiro, v. 3, n. 2, p. 9-50, 1996.

TERRA, D. V. Ensino crítico: participativo das disciplinas técnico desportivas nos cursos de licenciatura em educação física: análise do impacto de um projeto de ensino no Handebol. In: COSTA, V. L. M. (Org.). Formação profissional universitária em educação física. Rio de Janeiro: Universidade Gama Filho, 1997. p. 201232.

TRIVIÑOS, A. N. S. Introdução à pesquisa em ciências sociais: a pesquisa qualitativa em educação. São Paulo: Atlas, 1987.

Artigo derivado da dissertação de mestrado: "As disciplinas esportivas nos cursos de graduação em Educação Física: o exemplo do Atletismo".

Endereço:

Eduardo Vinícius Mota e Silva

Rua Alfredo de Vitto, 25 Pq. Recanto Parrilo

Jundiaí SP Brasil

13219-052

Telefone: (11) 3555.2131

Fax: (11) 3555.2190

e-mail: motaesilva@mackenzie.com.br

Recebido em: 3 de julho de 2009.

Aceito em: 26 de maio de 2011.

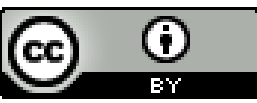

Motriz. Revista de Educação Física. UNESP, Rio Claro, SP, Brasil - elSSN: 1980-6574 - está licenciada sob Creative Commons - Atribuição 3.0 